\title{
"A questão feminina": revistas, afectos y mujeres en la reforma urbana de Rio de Janeiro ${ }^{1}$
}

\section{"A questáo feminina": magazines, women and affects in the urban reform of Rio de Janeiro}

\section{NATALIA LÓPEZ RICO}

\author{
Universidad de Bonn. \\ Correo electrónico: nlopezri@uni-bonn.de
}

El presenta artículo explora las revistas Kosmos y Renascença creadas durante los años más álgidos de la transformación urbana de Rio de Janeiro (1902-1910) como órganos de propaganda reformista. Nos detendremos en dos aspectos: la movilización discursiva de una retórica de los afectos como parte de la estrategia de renovación urbana y en la questáo feminina como una de las derivas de esta retórica. Si bien la participación de mujeres autoras en las revistas fue ínfima, se otorgó a la mujer un lugar prominente en el proyecto reformista como "guardianas del afecto". Así, al tiempo que se exigía de la mujer una moderada preparación intelectual (regida por principios positivistas comtianos), se le hacía responsable de resguardar y preservar los lazos afectivos que mantendrían la cohesión social urbana durante y después de las reformas.

Palabras claves: Rio de Janeiro, reforma urbana, mujeres, afectos.

The following paper explores the role of Kosmos and Renascença magazines as reformist propaganda vehicles during the peak of the urban transformation in Rio de Janeiro (1902-1910). The focus will be on two aspects: the discursive mobilization of the rhetoric of affects as part of the urban renewal strategy and the questâo feminina as one of the main outcomes of this rhetoric. While the participation of women authors in magazines was negligible, they were prominently displayed as the "guardians of affect" in the reformist project. Therefore, women were not only required to have a reasonable intellectual preparation, founded on Comtian positivist principles, but were also responsible for safeguarding and preserving the emotional ties that held urban society together during and after the reforms.

Key words: Rio de Janeiro, urban reform, women, affects.

\footnotetext{
${ }^{1}$ Este artículo forma parte del proyecto Fondecyt No 1180230 "Urbanidad, subjetividad y afectos en la narrativa contemporánea brasileña". Responsables: Horst Nitschack (investigador principal), Natalia López (co-investigadora). Agradezco a Horst Nitschack y a Elisabet Prudant la lectura, comentarios y sugerencias realizados al texto.
} 


\section{IDEAS INTRODUCTORIAS}

Espacios y afectos son términos que suelen aparecer cada vez con mayor frecuencia asociados a una variedad de estudios disciplinares que van desde las investigaciones urbanas empíricas sobre los efectos del espacio en la psiquis y las emociones de los cuerpos que lo habitan o atraviesan, hasta la considerable producción que la ya no tan novedosa teoría de los afectos o el llamado "giro afectivo" animó en el amplio abanico que integra los estudios culturales (literatura, historia, estudios visuales, entre otros) ${ }^{2}$. Que la ciudad tenga implicaciones afectivas en y entre las personas es una idea con una larga genealogía que podemos seguir con alguna certeza desde la sociología urbana moderna que tiene en los trabajos de Georg Simmel (1903) sobre los efectos de la metrópolis en la vida mental uno de sus más agudos aportes. En líneas gruesas, Simmel proponía que la modernización acelerada de las grandes urbes tenía impactos inesperados en la relación entre el individuo, la sociedad y la urbe, traducidos en una pugna entre la emoción y el intelecto con consecuencias en el modo de habitar la ciudad y en las expectativas tradicionalmente asociadas a la vida urbana. Desde entonces, uno y otro aspecto se han imbricado de tal manera que no se puede hablar de experiencia urbana sin dejar de referirse a un sinfín de adjetivos que dan cuenta de la intensidad afectiva desatada por ella, o, en palabras de Simmel, a la intensificación de estímulos nerviosos inherente al urbanitas moderno. ${ }^{3}$

Es precisamente esta densidad emocional la que de cierto modo recogen y analizan los trabajos que siguiendo las premisas teóricas del giro afectivo se centran en la relación estrecha y tensionada entre espacios, cuerpos y afectos, espacios donde se privilegian los entornos eminentemente urbanos aunque sin dejar de lado consideraciones en torno a la relación afectiva que establece el ser humano con la naturaleza, con el desierto, el sertón o las pampas, entre otros ${ }^{4}$. Estos trabajos se han propuesto ahondar en el reconocimiento y delineamiento

${ }^{2}$ El corpus de la teoría de afectos no para de ampliarse y tomar posturas diversas y a veces antagónicas. Para una revisión general recomendamos volver al archicitado libro de Patricia Ticineto Clough y Jean Halley (eds.), The affective turn (2007) y de Melisa Gregg y Gregory Seighworth (eds.), The affect theory reader (2010). Para América Latina los aportes de Cecilia Macón y Daniela Losiggio, Afectos politicos. Ensayos sobre actualidad (2017) de Mabel Moraña e Ignacio Sánchez (eds.), El lenguaje de las emociones. Afectos y cultura en América Latina y de Ana Peluffo. En clave emocional. Cultura y afecto en América Latina (2016).

${ }^{3}$ Una intensificación que bien podría desembocar en una actitud blasée, una suerte de parálisis emocional típicamente urbana a la que se llegaría por una excitación nerviosa prolongada (Simmel 4).

${ }^{4}$ No existe, hasta el momento, una postura común en la teoría de afectos frente a la diferenciación entre afectos, emociones y sentimientos. Para efectos de este artículo nos remitiremos a la distinción operativa propuesta por Eric Shouse (2005) a partir de su lectura de Brian Massumi. Para Shouse, el afecto sería una potencia pre personal, una intensidad no siempre consciente que incluso podría no pertenecer al ámbito del lenguaje sin que esto excluya su posible manipulación o modulación. La emoción, por su parte, puede ser expresión directa de los afectos así como la proyección o visualización de un sentimiento que puede ser transmisible, a veces como expresión del estado interno y otras como expresión de convenciones sociales. Los sentimientos, en cambio, serían personales y biográficos, estarían definidos por experiencias subjetivas anteriores y de ahí que sean distinguibles en cada persona si bien están determinados por lo social. De este modo, emociones y sentimientos funcionarían como traducciones sociales de los afectos. En la lectura del afecto como algo prepersonal y abstracto 
de mapas afectivos urbanos y paisajes afectivos que a su vez registran la potencialidad normalizadora y transgresora de los afectos, es decir, sus puntos de ambivalencia. ${ }^{5}$

Partiendo pues de la premisa indiscutible de que espacios, cuerpos y afectos se encuentran estrechamente vinculados, por lo general, de forma problemática y tensionada, este artículo busca explorar la movilización intencional de afectos en un momento y lugar determinados: el Rio de Janeiro bajo la reforma del prefecto Francisco Pereira Passos. Si el mundo urbano de principios de siglo XX se nos presenta como la apoteosis de la experiencia moderna que tanto expande como paraliza la capacidad de afectar y ser afectado (recordemos el choque benjaminiano como producto de la modernidad o el blasée de Simmel), más cabe esperar cuando esta modernidad urbana se instala abrupta y violentamente a través de planes reformistas que se pretenden totales. Fue este un proceso vivido por las grandes ciudades de Occidente, desde el emblemático caso del París de Haussmann o Berlín, hasta las capitales americanas, como bien muestra José Luis Romero en su célebre libro (1999). No obstante, cada caso pone de relieve condiciones culturales, políticas y económicas locales que los dotan de densidad propia y -lo que aquí nos interesa-, dan cuenta de una movilización de afectos particulares que tanto se censuran como se alaban o despiertan. En suma, y como trataremos de mostrar, las reformas urbanas instalaron dispositivos discursivos, en este caso revistas culturales, que apelaron a la necesaria destrucción de ciertos afectos que pretendían derrumbarse con la propia destrucción de la ciudad antigua, mientras se buscaba hacer emerger afectos nuevos relacionados con la reciente condición moderna de la urbe y se resignificaban afectos tradicionales, estos últimos asociados por lo general a lo femenino. Como vemos, este mapa afectivo bajo el contexto de renovaciones urbanas radicales bien se asemeja a la estructura de sentimientos propuesta por Raymond Williams (1988) con sus tres niveles: los sentimientos dominantes, residuales y emergentes que se ponen en juego en momentos de cambio (155). O en las palabras más precisas y recientes de Vladimir Saflate:

Quando sociedades se transformam, abrindo-se à produção de formas singulares de vida, os afetos começam a circular de outra forma, a agenciar-se de maneira a produzir outros objetos e efeitos. Uma sociedade que desaba são também sentimentos que desaparecem e afetos inauditos que nascem (Safatle 16).

radica, siguiendo a Shouse y a Safatle (2016), la consideración de cuerpos políticos amplios con capacidad de transformación inherente. Proponemos entonces la lectura de ciertas capas o derivaciones del afecto que permitan comprender o explicar qué afectos movilizan la construcción de lo común y qué otros refuerzan características de la subjetividad.

${ }^{5}$ La idea de mapas o cartografías afectivas se debe, ante todo, a los aportes más acabados de Jonathan Flatley quien se pregunta por las posibilidades de rendimiento analítico de afectos como la melancolía o la depresión. Véase Flatley, Affective mapping: Melancholia and the politics of modernism (2008). Por otra parte, los trabajos de Irene Depetris Chauvin se centran en los paisajes afectivos en el cine latinoamericano, entre ellos "Geographies of Love(lesness). Space and Affectivity in Viajo Porque Preciso, Volto Porque Te Amo (Aïnouz and Gomes, 2009) and Turistas (Alicia Scherson, 2009)" (2016) y "Ecos en el desierto. Paisaje, pueblo y afectividad en Sertão de Acrílico Azul Piscina" (2014), mientras Steve Pile ofrece una mirada panorámica a los principales debates en torno a los estudios de afectos, emociones y geografía en "Emotions and Affect in Recent Human Geography" (2009). 
Si bien la reforma de Rio de Janeiro implicaba un "colapso" controlado de la ciudad, el riesgo de un desborde afectivo ante la imagen y experiencia de la urbe en ruinas era inminente. La posibilidad de que esta aparente tabula rasa fuera malinterpretada o se saliera de los cauces delimitados por los planes reformistas tenía que ser acotada y direccionada. Así, en la implementación y difusión de un nuevo circuito de afectos urbano que debía traducirse e incorporarse en emociones y sentimientos colectivos e individuales puntuales, al desamparo producido por el contexto reformista se opuso la figura primigenia de la mujer que preserva y ampara.

A estas estructuras afectivas puestas en crisis responde el empeño intencionado de los agentes reformadores (ya sea estatales o privados) de poner coto a los ímpetus afectivos y emocionales a través del llamado a afectos tradicionales que podían traducirse o incorporarse en emociones como el amor femenino, maternal y apacible.

\section{LA CUESTIÓN URBANA: LA REFORMA DE LOS AFECTOS}

"A vida moderna é feita de relampagos no cerebro, e de rufos de febre no sangue". Olavo Bilac, Kosmos no 1

Con un poco de tardanza con respecto a sus pares latinoamericanas llegó el momento de la ansiada reforma urbana de Rio de Janeiro, por entonces capital de la recién erigida República de Brasil. Siguiendo el patrón de las tradicionales renovaciones urbanas operadas en capitales como Santiago o Buenos Aires ${ }^{6}$, el peso del proyecto recayó sobre un líder familiarizado con la reforma llevada a cabo por el Barón de Haussmann. Francisco Pereira Passos fue el Haussmann tropical elegido para encabezar la renovación carioca, un cargo en el que estuvo al frente como prefecto de la ciudad entre 1902 y 1906 ${ }^{7}$. En los inicios de su carrera diplomática Pereira Passos formó parte de la delegación brasileña en París y permaneció allí entre 1857 y 1860, tiempo en el que frecuentó los cursos de arquitectura, hidráulica, construcción de puertos, de vías de tren, entre otras, en la École de Ponts et Chaussées. Fue allí también donde presenció los inicios de las obras emprendidas por el prefecto nombrado por Napoleón III para la transformación de París. A su regreso, Passos fungió como uno de los ingenieros del Imperio haciéndose cargo de la construcción de las

\footnotetext{
${ }^{6}$ La importancia y rivalidad con el modelo bonaerense de renovación urbana es anotado en la revista Kosmos. El colaborador Thomaz Lopes, quien habría pasado una temporada en la capital argentina, anota al respecto: "Nós seguimos o louvavel exemplo que veiu de Buenos Aires, porque foram os Argentinos que inauguraram essa reacção, que abriram essa época de progresso, belleza, hygiene e conforto na America do Sul" ("Buenos Aires", Kosmos 3, 1908). La ortografía de citas de fuentes originales se mantendrá intacta.

${ }^{7}$ La denominación de "Hausmman tropical” fue desde la época de la renovación una manera común de designar a los reformadores. En otra crónica sobre Buenos Aires, el mismo Thomaz Lopes apunta que los porteños se referían a Pereira Passos como "el Haussmann de ustedes" ("Buenos Aires III", Kosmos 5, 1908). Véase también Benchimol Pereira Passos: um Haussmann Tropical. A renovação urbana da cidade do Rio.
} 
principales redes ferroviarias que unían la capital con importantes centros de producción agrícola y minera y acogió proyectos e intereses privados que más tarde desembocarían en la propuesta de transformación urbana de Rio de Janeiro, empresa que lideró al ser nombrado prefecto por el presidente de la república, Rodrigues Alves (Benchimol 1992: 210).

Los primeros informes de la comisión del proyecto de renovación urbana presentados en 1903 dan cuenta de los problemas que pretendían subsanarse:

O problema do saneamento do Rio de Janeiro foi sempre considerado, por todas as auctoridades que dele se têm ocupado, como dependendo em grande parte da remodelação architectonica da sua edificação e consequentemente da abertura de vias de communicação amplas e arejadas em substituição das actuaes ruas estreitas, sobrecarregadas de um trafego intenso, sem ventilaçáo bastante, sem arvores purificadoras e ladeadas de prédios antihygienicos (...).

É necessário melhorar a hygiene domiciliaria, transformar a nossa edificação, fomentar a construção de prédios modernos e este desideratum somente pode ser alcançado rasgando-se na cidade algumas avenidas, marcadas de forma a satisfazer as necessidades do trafego urbano e a determinar a demolição da edificação actual onde ella mais atrasada e mais repugnante se apresenta (Melhoramentos 4).

Con miras a expurgar la mala fama de urbe insalubre y pestilente que tan mal le hacía a sus relaciones comerciales con el mercado internacional, el saneamiento y la higienización se alzó como bandera de la reforma cuyo primer paso sería la renovación material que redundaría en la renovación moral de sus habitantes ${ }^{8}$. Pero fue justamente el foco puesto por los reformistas en la "higiene domiciliaria" el que más problemas planteó, convirtiendo al plan de transformación de Rio de Janeiro en una de las renovaciones urbanas latinoamericanas que más descontento despertó entre la población, cuya encarnación más radical fue la "revuelta de la vacuna", cuando las piedras y las ruinas de la ciudad se convirtieron en las armas y trincheras de los revoltosos.

\footnotetext{
${ }^{8}$ Con esta renovación material se dio un paso decisivo en la especulación urbana que marcará en adelante el destino de Rio de Janeiro, especulación que el mismo informe recién citado anota: "Releva considerar, porém, que as desapropriaçóes estáo calculadas na elevada base da Lei vigente e que, uma vez effectuadas, ficará a Municipalidade possuidora de terrenos com cerca de oito mil metros de frente nas novas avenidas, terrenos cuja renda produzirá por certo elevada quantia, pois que teráo inquestionavelmente maior valor do que actualmente tem. As novas avenidas têm uma extensão total de cerca de treze quilômetros e exigem a demoliçấo de 1.040 predios" (Melhoramentos 7).

${ }^{9}$ La revuelta de la vacuna, uno de los levantamientos populares más famosos del período, se dio en el marco de las reformas como respuesta al plan que pretendía vacunar a toda la población, en especial a la población pobre. Una de las críticas de la oposición era que los enfermeros, oficiales y policías encargados de administrar la vacuna, quienes entrarían en las casas y tocarían a las mujeres, eran personas conocidas por instintos brutales y "moralidad discutible". Véase Nicolau Sevcenko, A revolta da vacina. Mentes insanas em corpos rebeldes (1984).
} 
Así, entre 1902 y 1910 Rio de Janeiro se vio sometida a una reforma sistemática que cambió la cara y la fisionomía de la ciudad, especialmente en su zona central y cívica. A fin de difundir y ganar el beneplácito de las reformas y a la vez morigerar la desazón y calmar las sospechas, fueron creados diversos órganos propagandísticos financiados por la propia prefectura entre los cuales sobresalieron las revistas ilustradas. Revistas como Renascença y Kosmos se convirtieron - de forma más o menos explícita-, en portavoces de las reformas, dando cuenta detallada del proyecto reformista, de sus avances, de las demoliciones y primeras piedras que inauguraban los nuevos hitos urbanos modernos como el puerto y la Avenida Central, avances que se detallaban en crónicas, reportajes y fotografías. Tal como lo anunciaba el cronista Olavo Bilac en el primer número de Kosmos: "O Rio de Janeiro (...) vae pasar, e já está passando, por uma transformação radical. A velha cidade, feia e suja, tem os días contados. Esta revista acompanhará, se o publico quizer auxilial-a, essa lenta e maravilhosa metamorphose da lagarta em borboleta" ( $\mathrm{s} / \mathrm{p}$ ). La vieja ciudad, un lagarto serpenteante de calles estrechas por donde hacía menos de dos décadas se vendían y circulaban los esclavos que constituían el motor principal de la economía del país, figuraba en la revista como un pasado vergonzoso aunque superado, un capítulo de la historia que terminaba por sellar la reforma urbana que también contemplaba la borradura del Cais do Valongo, el lugar del puerto donde desembarcaban y se comercializaban otrora los esclavos y esclavas ${ }^{10}$. Las señales de la esclavitud -de la "raza torturada", como se le denominaba en Kosmos-, serían pues arrasadas dando paso a las grandes avenidas que "rasgarían" la ciudad, por donde desfilarían los nuevos dignatarios urbanos, una burguesía ascendente que también pretendía sacudirse los restos de la esclavitud que pesaba todavía sobre sus fortunas.

Las revistas parecían pues encarnar la medida de la civilización urbana a través de la glorificación de la modernidad que se instauraría con la reforma y también en la implementación de las más avanzadas tecnologías en materia de impresión. ${ }^{11}$ En sus textos, crónicas e ilustraciones, Kosmos y Renascença prefiguraban así un espacio urbano moderno, tan ideal y coherente como inalcanzable.

Si las crónicas, imágenes, ilustraciones y fotografías tuvieron como objetivo dar cuenta de la transformación urbana, la principal forma de vehiculizar el discurso reformista fue apelando a una retórica de los afectos. Con ese fin se perfiló una oposición de circuitos afectivos asociados a la ciudad antigua o colonial y a la ciudad moderna. La Rio fea, "retrograda, emperrada nas velhas tradiçóes" que yacía sobre "materiaes apodrecidos" se iba desmoronando gracias al himno que cantaban las piquetas: "con que alegria cantavam ellas, as picaretas regeneradoras!" ("Chronica”, Kosmos 3, 1904), dotando incluso a las propias máquinas encargadas de derrumbar la vieja urbe de cualidades emocionales que quedarían impregnadas en las nuevas avenidas que se abrían y en las plazas, parques y edificios que se

\footnotetext{
${ }^{10}$ Recientemente, en 2011, en el contexto de una nueva renovación portuaria se redescubrió el antiguo fondeadero Cais do Valongo, declarado Patrimonio de la Humanidad por la Unesco en 2017.

${ }^{11}$ De nuevo será Bilac quien señale que Kosmos fungía como la primera publicación periódica de lujo del país, de hecho es destacable la calidad de la impresión, las gráficas y el papel.
} 
alzaban. Esta misma disposición afectiva también sería un recurso utilizado al momento de calmar la angustia y el vértigo que producía la visión de la ciudad en ruinas: "o aspecto das ruinas contrase o coração e aterra o espíritu; receiase involuntariamente que toda aquella destruição seja uma cousa definitiva e irremediavel, que se tenha diante dos olhos uma cidade morta". Serían las almas de las antiguas generaciones las que contemplarían esta devastación como el fin de sus experiencias y recuerdos y debían despedirse de lo que amaron, odiaron, sufrieron y gozaron. Por eso el cronista principal de Kosmos, Olavo Bilac, recuerda que "do meio dessas ruinas surgirá em breve uma creação nova", la ciudad futura sacudiría los espíritus amodorrados de la ciudad antigua, apagada y triste, y las transformaciones del espacio habrían de modificar en la población " (...) seus habitos, influir sobre o seu carácter, activar a sua iniciativa, despertar-lhe o gosto do bello, o culto do ideal, o amor que se traduz por actos (...)" (Kosmos 9, 1904). Una idea de una civilización y civilidad plena alcanzada a través de la reforma material y el ímpetu del prefecto Pereira Passos quien habría operado "o milagre da transformação: corrigio habitos grotescos, e substituio ruas hedionadas por outras bellas, inteiramente novas" ("Dr. Franciso Pereira Passos", Kosmos 2, 1905).

Tras la insistente diferenciación de la imagen del Rio antiguo y el Rio moderno subyace sin duda la firme intención de convencer a los lectores de Kosmos y Renascença en particular, y a la población en general, de que, en efecto, se trataba de reformas radicales que fundaban una ciudad nueva y una nueva experiencia del tiempo. La aparente conciencia de la rapidez de la transformación y la convicción de ser testigos y partícipes de un momento sin precedentes se deja traslucir en crónicas y relatos que hablan de una "nova éra da vida urbana", la sensación de que en "cada mez, a cidade progride um anno". En los términos más extremos que propone el cronista Bilac, Rio llevaba 402 años dormida y solo 5 años despierta ${ }^{12}$.

No obstante, la ciudad moderna no estaría exenta de los asaltos, no solo violentos sino también afectivos, de la antigua ciudad -o de la nueva ciudad bárbara que se habría duplicado con la renovación, las expropiaciones y la consecuente crisis habitacional-; una porción urbana que se equiparaba ahora a la ciudad de arriba, la ciudad de los morros que bajaba con sus cuchillos y navajas, pero también con su alegría y gozo desbordante en el carnaval y en las festividades religiosas. Esta porción salvaje a la cual la ciudad civilizada daba la espalda volvía así sobre la ciudad nueva, su antiguo territorio, en cada festividad a "perturbar e envergonhar a vida da cidade civilisada" ("Chronica”, Kosmos 10, 1906). En esta campaña, Renascença presenta una serie de artículos dedicados a plasmar crónicas e imágenes sobre las antiguas calles y rincones de la ciudad, panoramas que "felizmente, vão dessaparecer com a construcção da Avenida Central. É preciso, porem (...) que esse Rio de Janeiro, onde taes aleijōes se encontram, crie vergonha e se transforme" "Chronica",

\footnotetext{
${ }^{12}$ Una idea que justamente pone en duda la investigación de Paula de Paoli que detalla con sumo cuidado toda la estructura antigua, especialmente las viviendas que sobrevivieron o se mantuvieron en medio de las calles reformadas. Para de Paoli, la transformación, al menos en sus inicios, habría sido más discursiva que real. Véase Paula de Paoli, Entre relíquias e casas velhas. A arquitetura das reformas urbanas de Pereira Passos no centro do Rio de Janeiro (2013).
} 
Renascença 3, 56). La intención de hacer circular determinados afectos queda aquí manifiesta y no resulta casual que sea justamente la vergüenza la emoción movilizada, una emoción que implica dar la espalda, no poder mirar ni reconocerse en esa supuesta ciudad del pasado (Ahmed 2015: 165). Ya Norbert Elias demuestra cómo la formación del sujeto moderno se hizo bajo el mandato de emociones como el pudor y la vergüenza, que permitían no sólo remarcar y diferenciar comportamientos de clase y distinguir la civilización de la barbarie sino también aglutinar y crear un nuevo sentido de lo común.

El insistente llamado a movilizar afectos repulsivos contra la ciudad vieja no pareció, sin embargo, dar los resultados esperados. Más bien se potenció la emergencia, intempestiva y casi artificial, de un pasado marcado por los anhelos y nostalgias por lo perdido, activando un nuevo registro urbano desde la memoria que dotó a la ciudad de una inesperada valencia afectiva. Abundan así los relatos dedicados a estampar las librerías, cafés, confiterías, fábricas de cigarrillos, casas de prensa, billares e incluso cabarets, escritos en clave nostálgica, el "Rio de outrora", o la "recordação de um tempo" que se sabía o simulaba perdido por la irrupción del progreso, un progreso que, como hemos leído, también se nombraba como rasguño o herida urbana, cuyo símbolo por excelencia fue la Avenida Central.

Una intencionada gramática de los afectos fue así desplegada con el ánimo de movilizar un doble circuito afectivo urbano que delineaba y contraponía el Rio antiguo y el moderno: el primero, determinado por la vergüenza, la tristeza y la repugnancia, pero también la alegría desmedida de la ciudad que se pretendía borrar, y el otro por el pudor, la felicidad y el júbilo moderado que demandaba una ciudad que se preciara de su modernidad. Lo que se escapó al cálculo fue el surgimiento de un circuito inesperado comandado por emociones como la ańoranza y la memoria de la ciudad desaparecida, en especial por la sociabilidad estrecha que las mismas calles estrechas que debían odiarse habían propiciado, y que las grandes avenidas impersonales desterraron.

En medio de la oleada de los afectos circulantes lo que parecía más claro es que la ciudad vivía tiempos vertiginosos y ante el vértigo de la transformación uno de ellos tendría que permanecer impasible: el amor que sólo podía sentir y expeler la mujer.

\section{LA CUESTIÓN FEMENINA: LA MUJER GUARDIANA DE LOS AFECTOS}

En las primeras décadas del siglo XX el campo cultural brasileño contaba con algunas autorías femeninas notables -merced al lento proceso de inserción de las mujeres en la esfera pública y letrada- ${ }^{13}$, pero Kosmos y Renascença prescindieron de su presencia activa. Tan sólo se cuentan dos colaboraciones de Júlia Lopes de Almeida en la revista Kosmos en

\footnotetext{
${ }^{13}$ Este proceso se encuentra ricamente descrito en la tesis de Carol Arcos Herrera, Autorías femeninas fundacionales: escritoras chilenas y brasileñas del siglo XIX. (1840-1890) de 2014 y en el pionero trabajo de Dulcília Buitoni Imprensa feminina de 1986. También encontramos referencias significativas en Norma Telles "Escritoras, escritas, escrituras" (2006) donde reseña, por ejemplo, el periódico O Corymbo de las hermanas Revocata Heloísa de Melo y Julieta de Melo Monteiro, que funcionó entre 1844 y 1944 (426).
} 
1905 y 1906, cuando gozaba de una sobrada reputación como mujer de letras y sus novelas eran un éxito de ventas. Las dos colaboraciones de Almeida tratan, no obstante, de temas en apariencia menores, quizás siguiendo las crónicas y artículos ligeros que caracterizaban la revista, a diferencia de Renascença que solía incluir en ocasiones artículos científicos o ensayos extensos.

Que la primera colaboración de la autora se titule y dedique a los "Flamboyants", tipos de acacias que habían desaparecido con las reformas de la ciudad, no es fortuito. En varios de sus artículos Almeida mostró preocupación por la urbanización, alentando una airada defensa de la ciudad jardín que se tradujo en pequeñas victorias: tras insistir con notas en la prensa, las reformas no arrasaron con el morro de Santo Antônio (Telles 456) ${ }^{14}$. En el artículo de Kosmos Almeida señala que los flamboyants habrían sido desterrados por su condición de planta estacional que mudaba y se deshojaba en invierno. La mancha verde negra que exhibía pues la planta en la estación invernal, junto a las cigarras que en ella se refugiaban y cantaban, habrían desaparecido. La de Almeida era una de las voces nostálgicas de la vieja Rio, si bien en el pequeño relato su lamento es una emoción marginal frente al frenesí moderno y reformista. Así misma se define entonces como

alguem tão pequenina que o seu grito mais clamoroso se perdería a curta distancia, como um suspiro (...) alguem que, para conforto das cigarras e alegria das florestas, gostaria de plantar, aque e além (...) os maravilhosos flamboyants de umbellas luminosas, esplendendo ao sol! (Kosmos 12, 1905).

Más que los afectos y emociones humanas, lo que le interesa a Almeida es la comodidad de las cigarras y la alegría de la selva, dotando a la naturaleza de capacidades afectivas que en la Rio moderna no tenían cabida. La segunda y última contribución de la autora, "O gesto", se dedicaba -como bien el título lo indica-, a la importancia de la gestualidad con su protagonismo decisivo en la comunicación y en el lenguaje. La autora volverá a aparecer en la revista en el ańo 1907, esta vez retratada por uno de los célebres artistas brasileños del momento, Rodolpho Amoedo (Imagen $n^{\circ} 1$ ). En la imagen puede observarse a Almeida en su propio despacho, con la postura y gestualidad de una mujer dueña de sí, su actitud no es la de la típica mujer erguida y se distingue en cambio una curva moldeada por el oficio de mujer de letras que permanece largas horas con la cabeza gacha frente a las hojas en blanco que rellena en su mesa.

\footnotetext{
${ }^{14} \mathrm{Su}$ reconocida pasión por las flores y jardines se tradujo en la creación de un mercado de flores bajo su recomendación y auspicio y un manual de jardinería Jardim florido de 1922 (Telles 440).
} 
Imagen $n^{\circ} 1$. Kosmos 6, 1907.

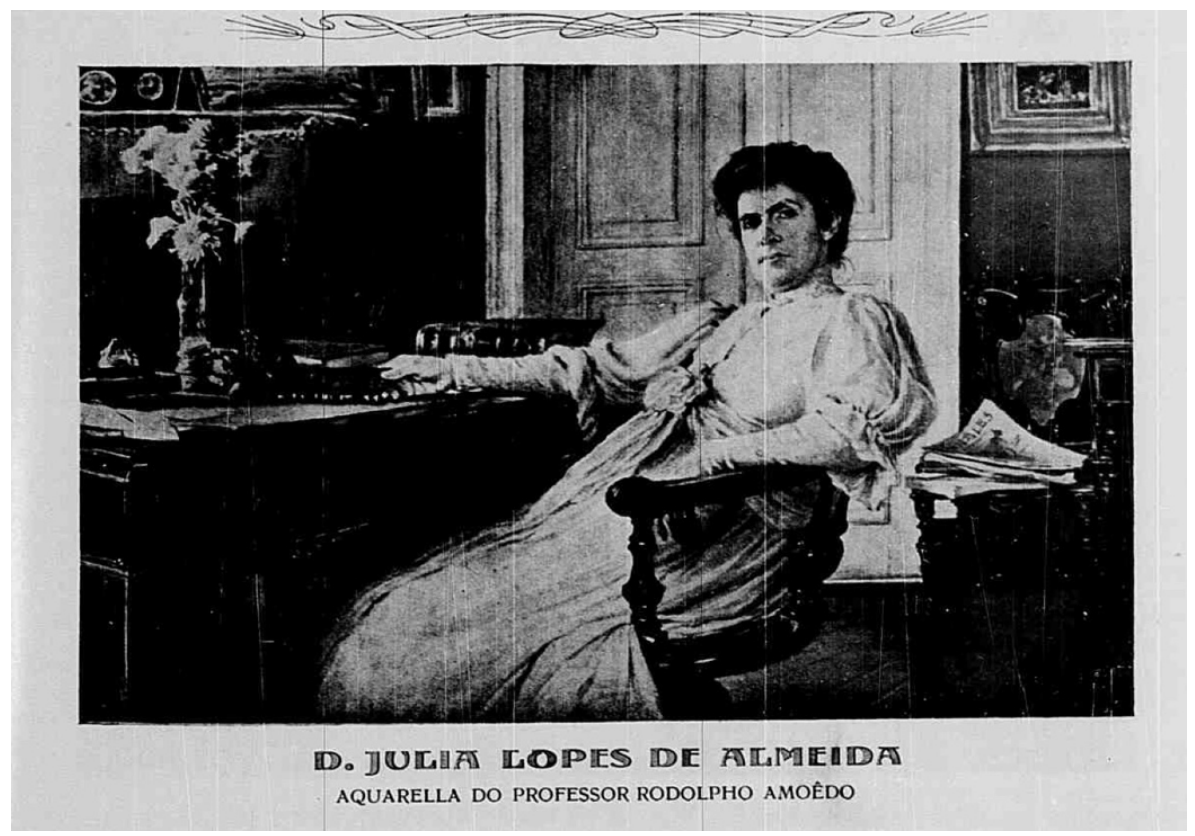

Aunque sin duda en la imagen de Almeida se ensalza la figura de la mujer de letras, las revistas no perfilan decididamente a una lectora femenina siendo contadas las ocasiones en las que los articulistas nombran a sus interlocutores como mujeres. En una de estas ocasiones Olavo Bilac se refiere a la "linda assignante de Kosmos que n`este momento me estás lendo" $(8,1905)$, una mención que más parece una estrategia publicitaria para atraer nuevos suscriptores que a un llamado real. En esta crónica, Bilac propone erigir el 15 de agosto como el día de la "Glorificação da Mulher" con miras a reemplazar la festividad religiosa de la asunción de la virgen. Se trataba de una típica estrategia del Positivismo, que tanta fuerza y repercusión tuvo en el Brasil de la Primera República: el operar una suerte de sincretismo que cambiaba las festividades religiosas por celebraciones laicas y civiles creando de este modo el nuevo calendario positivista ${ }^{15}$. La propuesta de Bilac se cerraba con la promesa de celebrar el día de la "Influencia social da Mulher" el 15 de agosto del año siguiente, 1906, y de ahí en adelante. La propuesta nunca llegó a concretarse.

Lo que sí se llevó a cabo con ahínco fue una campańa discursiva a favor de posicionar a la mujer como centro del debate. Más allá de las apariciones sueltas pero significativas de las propias mujeres y de temas a ellas referidos, consideramos pues que la questão feminina

\footnotetext{
${ }^{15}$ Para una visión acabada del Positivismo en Brasil uno de los libros clásicos es el de Ivan Lins, História do positivismo no Brasil (1967).
} 
fue un eje que atravesó el periodo con densidades diferenciadas, lo que mejor se vislumbra en la revista Kosmos a lo largo de su existencia, publicación en la que nos enfocaremos a continuación.

La cuestión femenina es susceptible de ser abordada en tres momentos: un primer momento dominado por la idea de la mujer afectiva que corresponde a la época de demoliciones y a la visión de la ciudad en ruinas; el segundo momento lo hemos denominado la mujer decorativa correspondiente al levantamiento de edificaciones y a la inauguración de la Avenida Central; en el tercer momento se vislumbra la intervención efectiva de la mujer pública, cuando buena parte de las reformas pilares se concluyeron y la ciudad empieza a desenvolver un tipo de sociabilidad inherente a la nueva disposición espacial urbana. Trataremos el primero de estos momentos en detalle dado el fuerte despliegue de la retórica afectiva que lo marca, una densidad afectiva que no parece tan decisiva en los momentos que le siguen, los cuales sólo serán reseñados.

En los cuatro primeros números de Kosmos, publicados entre enero y abril de 1904, el colaborador Reis de Carvalho dedicó sendos artículos a plantear sus consideraciones en torno a lo que llamaba el urgente problema del quiebre entre el hombre y la mujer, artículos que tituló "A questão feminina", divididos en seis apartados que contrastaban la "verdadeira theoria feminina" con la "monstruosa doutrina feminista".

Reconocido integrante del apostolado positivista, Carvalho se vale de un discurso típicamente comtiano para plantear el problema femenino que a su modo de ver se traducía en insoportables e incompatibles vidas al interior del hogar, una suerte de queja que casi trasluce una situación personal. Las principales amenazas vendrían de dos frentes opuestos: en el primero de ellos estarían los doctores de la metafísica, en alusión a las corrientes filosóficas materialistas que se abrieron paso en el siglo XIX, quienes habrían intentado "esterilisar o coração da mulher infiltrando-lhe o virus corrosivo de uma sciencia que rebaixa o espíritu e atrophia o sentimento", arrancando de las mujeres "esse resto de cultura affectiva que o Catholicismo lhes ministrou" $(1,1904)$. Del otro lado estarían los metafísicos retrógrados que consideraban a la mujer un ser inferior y abogaban por su permanencia en situación de semi esclavitud bajo la tutela y al servicio del hombre. Ni unos ni otros daban con la solución a lo que Carvalho consideraba como el gran problema del momento: "o problema feminino que, com a questáo proletaria, constitue o objeto principal dos esforços de todos os coraçóes animados por um verdadeiro amor social". El articulista entrevé y equipara pues las dos grandes fuerzas que surgirán con ímpetu en los albores del siglo XX y que marcarán la agenda política y social en adelante: la cuestión femenina y la cuestión obrera.

Lo que interesa a Carvalho es ofrecer la solución al problema femenino, una solución que, según el autor, ya habría sido formulada cincuenta años antes por Augusto Comte en su filosofía positiva, "inspirada pelo amor e demostrada pela sciencia", teniendo como ciencia a la sociología inaugurada por el pensador francés que revelaba las supuestas leyes inmutables de lo geométrico y lo social.

El delineamiento de la solución parte con la diferenciación del cerebro y el alma masculina y femenina, un alma que en su definición científica sería "o conjuncto das funçóes 
do encephalo", compuesta de sentimiento, de inteligencia y de voluntad: "amar, pensar e agir é a triplece função de todas as almas" $(2,1904)$. Por encima de estas funciones, la que gobernaría a las demás sería el sentimiento, el amor, pues incluso el mismo funcionamiento del cuerpo dormido que mantendría pal pitante al corazón se daba gracias a la "acção continua dos motores affectivos". La inteligencia, y por tanto, la acción, quedaban pues sometidas -según la filosofía positiva-, al sentimiento: no se podría tener una gran idea y mucho menos actuar "sem ser inspirado por uma forte affeição". De este modo, las diferencias estarían dadas por la calidad de los sentimientos que podrían ser egoístas o altruistas. Es fácil suponer a qué género corresponderían unos u otros sentimientos: la consecuencia lógica y científica positiva desemboca en que entre los dos seres, hombre y mujer, "o superior é o que mais ama e não o que é mais sabio ou mais activo". Nombrado como el sexo afectivo o sexo amante, las mujeres estarían marcadas por esta afectividad inconmensurable de madres, esposas e hijas, "entes femininos que cercam na existencia domestica". Esta superioridad femenina afectiva, que propiciaba la convivencia y el orden social y que frenaba los ímpetus violentos masculinos, era reconocida así junto a su inferioridad intelectual.

Hasta este punto la cuestión femenina estribaba en el reconocimiento de la mujer como sexo superior afectivo e inferior intelectual, y como fuente, soporte e inspiración masculina. El positivismo hace suyo el lema devenido cliché de que la mujer "não produz as grandes obras, mas forma os grandes homens", su gloria yacería en la calidad "dos homens que educa, dos homens que seu amor dirige, como mai, esposa ou filha". En suma, de esta comparación de las cualidades cerebrales se concluía que la mujer era superior al hombre en sentimiento, igual al hombre en inteligencia e inferior en actividad. Es decir, la voluntad y la agencia femenina quedaban descartadas decretándola una verdadera presa de la domesticidad y de sus emociones.

Los siguientes aspectos tratados en la "questão" ahondan en esta emocionalidad femenina restringida -tal y como quedó establecido-, al ámbito doméstico, a la relación marital y a la familia como el núcleo social. Augusto Comte habría instituido la

(...) união conjugal, a monogamia indissoluvel e eterna, e, resumindo as condiçóes dessa sublime união, que elle chamou -uma verdadeira amizade aformoseada por uma incomparavel posse mutua-, formulou-as nestra tríade táo racional quanto afecctiva: virginidade previa, fidelidade continua e viuvez eterna (3, 1904. Cursiva del original).

Una triada "racional y afectiva" que no sólo vuelve sobre la restricción de la mujer a las emociones sino también a los límites de su cuerpo en un solo hombre para su vida, argumentos que de paso utiliza Carvalho para declararse contrario a las leyes de divorcio que por entonces se discuten en Brasil. A la par, deja escapar sus temores frente a la "doutrina feminista" que masculinizaba a las mujeres y las animaba a concurrir a las funciones y esferas públicas. Un intento frenado por "o bom senso popular, aliado ao criterio philosophico dos verdadeiros pensadores". Ninguna vocación pública tendría cabida en las mujeres habida 
cuenta de que su única vocación posible sería la del amor, un amor que se traduciría en obediencia, pues "quem não obedece nấo ama", un amor que aunque descrito en clave social y relacional era apenas una extensión del amor romántico en su vertiente sacrificial y normalizadora.

De la superioridad afectiva y moral de las mujeres y de su existencia cada vez más restringida al hogar se desprendía que la función principal radicaba en educar a los hombres. Con ese fin debería ser entregada una instrucción femenina apenas justa que cuidara no hacer de la mujer un ser puramente letrado, volviéndola triste ejemplo (como Staël o Georges Sand), de un espíritu lleno de talento animado por un corazón y sentimientos depravados. Las lagunas intelectuales serían saciadas por el mismo positivismo que habría formado profesores enciclopédicos encargados de entregar lecciones de sociología, biología, química, física, astronomía y matemáticas. En Rio de Janeiro el encargado de esta instrucción era el conocido apóstol positivista Teixeira Mendes, quien desde 1897 dictaba un curso enciclopédico destinado a las adolescentes. La instrucción tendría pues una aplicación exclusivamente doméstica procurando que la mujer cumpliera sus aspiraciones del "coração, de espirito e de carácter, sem sahir do convivio domestico (...)", pero tenía una finalidad pública: el corazón femenino dirigía indirectamente a la sociedad.

La era de regeneración humana que alentaba el positivismo dependía pues en su punto esencial de la adhesión femenina a esta, una adhesión que tal como lo declaraba Carvalho sería posible manteniendo "1. A existencia domestica da mulher. 2. Sua independencia de todo o trabalho exterior". Solo entonces la mujer encontraría su verdadero lugar en la sociedad como "o mais perfeito símbolo da Humanidade" $(4,1906)$.

"A questão feminina" que presenta Reis de Carvalho podría parecer apenas anecdótica y casi ridícula sino fuera una manifestación transparente de una matriz de pensamiento que tuvo en Brasil una repercusión inusitada desde mediados del siglo XIX hasta bien avanzado el siglo XX gracias, en parte, a la fuerza con que implementó su propio circuito de afectos. Quizás por la estrecha relación que desde muy temprano se estableció entre algunos intelectuales brasileńos con el mismo Augusto Comte, el Positivismo tuvo una enorme figuración en la política brasileńa hacia fines del Segundo Reinado y, sobre todo, en la formación y puesta en marcha de la Primera República. Incluso Nísia Floresta, en su estancia en Francia, fue una de las mujeres más cercanas a Comte, quien depositó en la joven viuda brasileña la esperanza de difundir entre las mujeres el positivismo en las zonas meridionales, tal como da cuenta en una carta que envía a Pierre Laffitte, refiriéndose al Opúsculo Humanitário, artículos sobre la educación femenina, que la autora había publicado en portugués en 1853: "(...) inspira-me sólidas razóes para esperar se torne a nobre dama, sua autora, dentro em breve, uma digna positivista, susceptível de alta eficacia para a nossa propaganda feminina meridional" (Citado en Lins 20). Mientras para Florestas: "Não será a espada, mas o amor, que regenerará o homem; o cristianismo o prega em vão há perto de 1900 anos. Esperemos que a religião geral da humanidade o realize um dia" (Citado en Lins 25. Negrita nuestra). La centralidad que, como hemos podido observar, otorgaba Reis de Carvalho al amor como base social tomada de la matriz positivista, es una de las 
razones por las cuales la filósofa Martha Nussbaum vuelve sobre el positivismo de Comte en su exploración de proyectos filosófico políticos normativos que tuvieran como eje las emociones. El cultivo social del amor y la simpatía eran las bases de la "nueva religión de la humanidad" que se propuso erigir el positivismo, sentimientos que se cultivaban en las esferas familiares pero cuyo fin era ampliarse hacia una especie universal. Las madres cumplían pues un papel fundamental (el símbolo comteano era una mujer que sostenía un niño en brazos), aunque cumplían sus funciones en base a rituales minuciosamente pauteados en el Catecismo positivista. Se le daba pues a la mujer "(m)ucha centralidad pero ningún poder político" (Nussbaum 2014: 88), con lo cual se ahondaba aún más la diferencia entre los géneros. La supuesta solución de Reis de Carvalho no podría pues estar más lejos de cumplir su cometido apaciguador de la questâo feminina; su invocación a la afectividad de la mujer no solo reforzaba la pasividad y el encierro doméstico de todo un género sino que también pretendía frenar las posibilidades y aspiraciones que auguraba el derrumbamiento de la antigua Rio.

De hecho, no es de extrañar que la questão feminina se invocara justo en el momento en que se daba inicio a los trabajos y la ciudad tenía el aspecto de un campo de batalla. Es precisamente en los números del primer año de Kosmos en los que las imágenes de la ciudad en ruinas vienen acompañadas de figuras femeninas cuyos semblantes transmiten una placidez y una ternura que parecen calmar el vértigo de la transformación (Imagen no 2 y 3). Las mujeres devienen así en figuras guardianas de los afectos maestros que tambaleaban y se resquebrajaban con la fuerza demoledora de las reformas. Fueron convertidas en símbolos que articularon una supuesta unidad pública no sólo a nivel de la ciudad si no también nacional, aunque en el discurso de la questão feminina su lugar se restringiera a las paredes de sus casas, las mismas casas que se derrumbaban tras las expropiaciones.

El amor republicano y cívico encarnado en la figura de la mujer era así resignificado y ganaba otro peso en tiempo de reformas. Si bien, como recuerda Arcos (2014), la cuestión femenina no fue solo un tema tratado por hombres y por el positivismo dado que desde la segunda mitad del XIX fue discutido por "las propias mujeres que participaban en prensa y revistas" siendo ellas "las encargadas de instalar públicamente temas atingentes al ingreso a la educación y la profesionalización" (176), el reforzamiento de dictados conservadores que a partir del discurso ambiguo del positivismo le otorgaba a la mujer el mayor protagonismo y peso social y la menor capacidad de acción política y pública, responden a la urgencia reformista de la cual habría que salvar las bases de un orden social que aunque mínimo o inexistente, era posible conservar o fraguar en la fuerza afectiva femenina.

Superada la primera fase reformista e inaugurada la Avenida Central -el hito de las reformas-, la cuestión femenina fue perdiendo densidad cediendo a un discurso más ligero en torno a las mujeres que incluso asomaban con más frecuencia en las fotografías de la ciudad de Augusto Malta y en las propias crónicas que daban cuenta de la sociabilidad que los nuevos espacios urbanos animaba.

La mujer decorativa hizo su aparición en las crónicas e imágenes urbanas dotándola de una ligereza y gracia típicamente moderna y reconociendo a la ciudad como un ente 
Imagen 2 y 3. Kosmos 9, 1904.
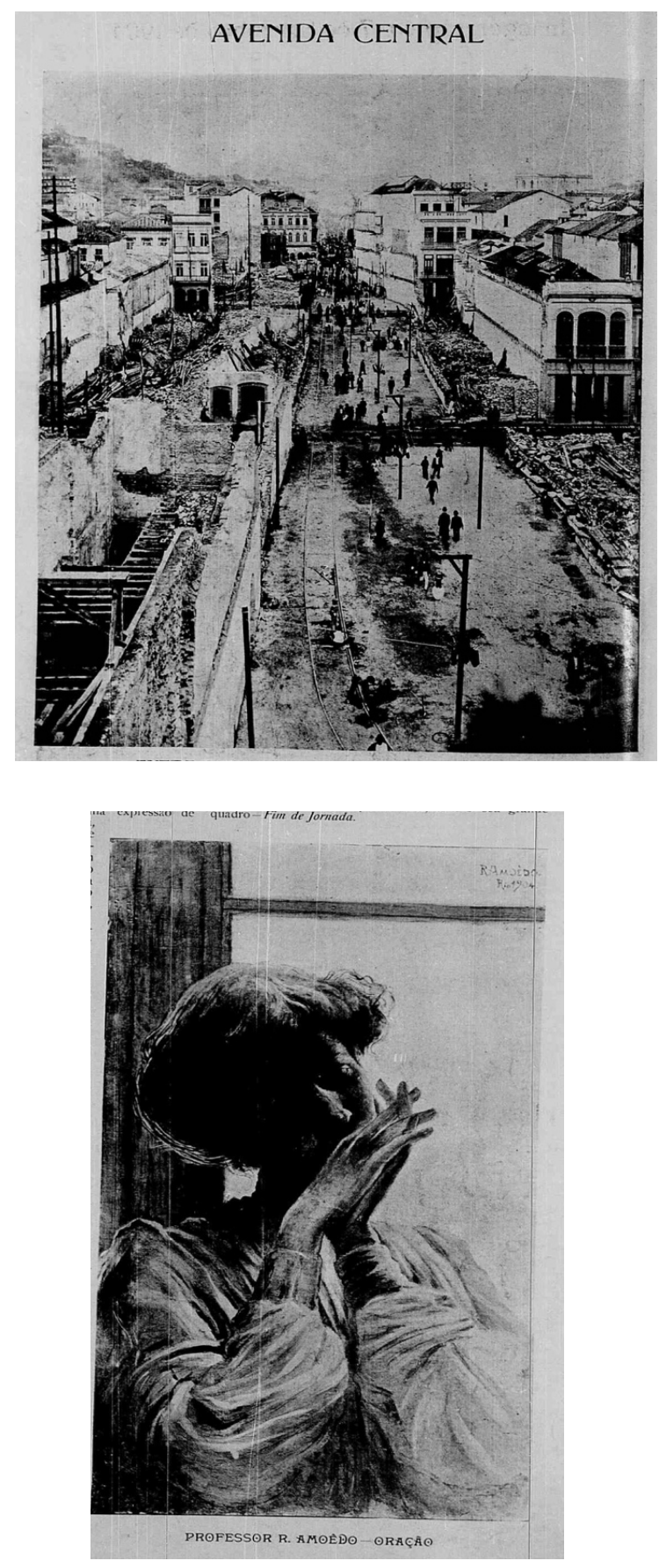
femenino. El mejor y más llamativo ejemplo lo encontramos en la crónica "A mulher e a rua" escrito por un cronista que firmaba con las iniciales M. P. ${ }^{16}$. El cronista recrea un paseo por la Avenida Central de la mano de un amigo, y es ahí en la Avenida que perciben que "hoje, até as mulheres são mais lindas" $(11,1907)$. Las causas de esta belleza renovada las encuentra en que la mujer "sofre, como a cidade, os beneficios da civilização". Una civilización simbolizada por la calle, principalmente por la nueva avenida. En las antiguas calles estrechas, como la famosa calle Ouvidor, las personas caminaban hombro a hombro, sin una perspectiva que permitiera apreciar a la mujer mientras los malos adoquines le quitaban cadencia a su andar. Por el contrario "Com as ruas amplas, com a moldura alegre das casas novas, o movimento e o jesto podem obedecer a todas as exijencias e aos rigores de todos os estudos, e o proprio passo pode ter a cadencia que a toilete demanda". El cronista concluye con el dictamen de que "A belleza feminina pede ruas largas", justificando la implementación de las reformas como medida necesaria para el despliegue erótico y público de la mujer, componente del renovado circuito urbano afectivo.

El último momento de la cuestión femenina tratada en Kosmos que hemos denominado como la mujer pública, hace referencia a una incipiente pero significativa apertura de la discusión que admite la figuración de las mujeres no solo como decoración urbana sino también como fuerza de trabajo del capitalismo moderno, e incluso se da paso a algunas voces femeninas, aunque solo haya sido bajo el formato de citas.

Podemos reconocer el inicio de esta fase en la reseńa de una conferencia dedicada a la mujer dictada en noviembre de 1908 por Enrico Ferri, integrante vital del partido socialista italiano y furibundo positivista. Aunque no se publica íntegramente el contenido de la charla, en la crónica principal de Kosmos -escrita entonces por Gonzaga Duque-, se extraña que las señoras que "de quando em quando se aventuram á exibição publica na tribuna das conferencias da moda" ("Chronica", 11, 1908), no se hubieran manifestado en contra de la supuesta defensa de la mujer realizada por Ferri. En el mismo número de la revista, André de Resende ofrece un texto titulado "Quatro feições femininas" que vuelve sobre la conferencia del político italiano. Para Resende, después de la conferencia sobre la mujer se habría levantado "uma verdadeira celeuma a este respeito". El ruido habría despertado voces de todos los bandos, voces que coincidían en defender al "chamado sexo fraco", si bien el articulista señalaba con especial atención la opinión dada por Teixera Mendes en la misma conferencia (el profesor enciclopédico de las adolescentes positivistas, citado más arriba), quien "chegou a afirmar que o homem tem o deber absoluto de sustentar a mulher, o que pôz calofríos nos que andam a pasar no modo mais pratico de conciliar a deprimente carestia da vida carioca com a exiguidade dos vencimentos e salarios", un claro reconocimiento no solo del encarecimiento de la vida urbana sino de la demanda que el capitalismo hacía por integrar esta nueva fuerza de trabajo. Las cuatro características

\footnotetext{
${ }^{16}$ Lamentablemente no hallamos información sobre el autor al que corresponden las iniciales. Por la revista Kosmos desfilaron gran parte de los principales cronistas de la época: Olavo Bilac, João do Rio, Gonzaga Duque, entre otros.
} 
femeninas que trae a cuento el articulista son la belleza, el amor, el pudor y la coquette, cuatro rasgos que dotaban a la mujer de una complejidad y heterogeneidad no considerada por el positivismo. Para describirlos, Resende lanzaba unas pocas líneas propias y luego citaba lo que otros "notables" habrían dicho al respecto. Lo más interesante ocurre en la imagen que caracteriza al amor y las citas que trae a cuento, una de Madame de Staël y otra de George Sand: "o amor é como a fé nos milagres: é um trabalho da imaginação para excitar o coração e paralysar o raciocinio".

\section{Imagen n4. Kosmos 11, 1908.}

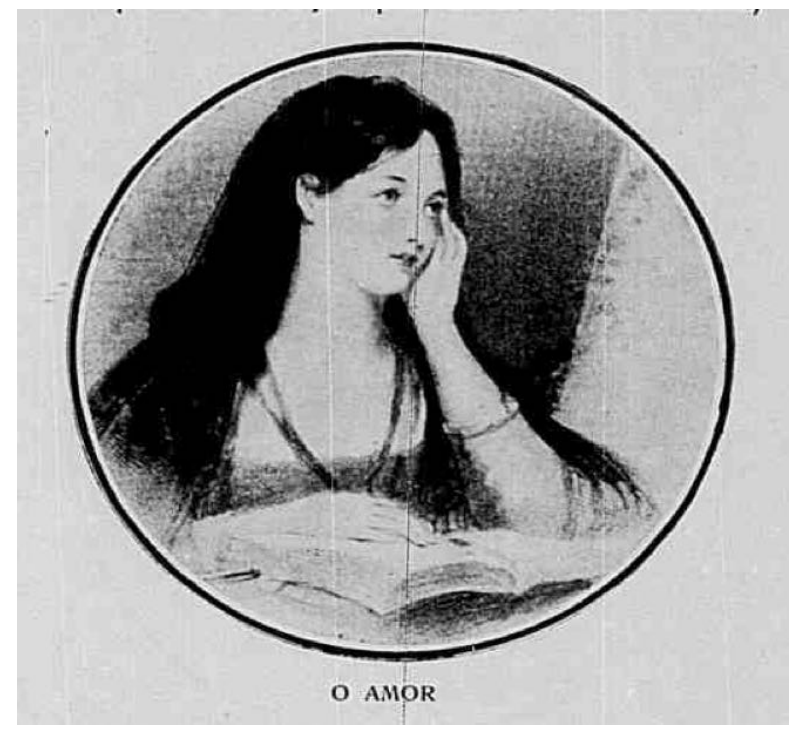

En la imagen de una típica lectora romántica suspendida en la ensoñación de la lectura, parece estar operando el milagro del que habla Sand: el amor entre la excitación y la parálisis; el amor como excitación subjetiva que nubla el juicio y la parálisis de la razón y no como fuerza social cohesionadora.

En el simple gesto de ironizar los dichos de Teixeira Mendes y dar cabida a las citas de letradas eminentes se vislumbra una tímida apertura hacia modos de feminidad diversos así como una vuelta a la idea del amor no natural, a una construcción imaginaria que contestaba y se oponía a la razón social productiva. Pero el articulista vuelve sobre un cliché y cierra su colaboración señalando que "a mulher, com todos sus defeitos e todas as suas virtudes, bella, amorosa, casta, pudorosa, coquette far-se-á amada... conforme os paladares dos homens. Os gustos são relativos". La pretendida diversidad de mujeres quedaba pues apenas sujeta al apetito masculino para los cuales su existencia estaba dispuesta. 


\section{A MODO DE CIERRE}

Hemos intentado mostrar la manera en que agentes encargados de la transformación urbana de Rio de Janeiro emprendieron una campaña pro reformista que tuvo como pivote una gramática de los afectos desplegada en las revistas culturales. La promoción de una nueva relación entre individuos, grupos sociales y entorno urbano se valió de la modelación de emociones que debía suscitar la propia transformación y la implementación de un plano moderno que exigía, asimismo, actitudes y emociones ad hoc. En suma, era necesario implementar otro circuito afectivo que delineara un nuevo sistema sensorial urbano.

Con ese fin, el discurso afectivo intentó a la vez sumir a los urbanitas en el goce de la transformación proponiendo una forma renovada de ser y estar en la ciudad o, en palabras de Simmel, animar una suerte de estimulación nerviosa urbana, y poner coto a los impactos inesperados que podría despertar la renovación. Un cálculo, como observamos, realizado sobre un equilibrio inestable que no tardó en revelar sus grietas demostrando de qué modo, cuando de afectos se trata, se opera siempre sobre puntos de ambivalencia a partir de los cuales cabe esperar, retomando la cita inicial de Safatle, el surgimiento de afectos inauditos, algunos en situación de latencia o, incluso, corto circuitos afectivos cuya manifestación más plena durante la reforma fue la Revuelta de la vacuna.

La reacción frente a lo inesperado fue el llamado a la afectividad femenina tradicional como fuente de lo inmutable, una idea especialmente consagrada por el positivismo en general, y por el practicado en Brasil en particular. El amor femenino, duradero y apacible sería el punto de conservación de los antiguos valores patriarcales que debían traspasarse intactos de la antigua a la nueva urbe, sin considerar qué caminos inesperados llevaban cultivando por años las mujeres en Brasil, algo que en la revista es reseńado por los autores y articulistas apenas como casos de excepción o como figuración pública urbana decorativa o erótica. Así, en la progresiva tematización de lo femenino sea como reservorio de la afectividad social, como figura decorativa o pública o como nuevo agente del capitalismo moderno, subyace la intención de mantener el dominio de la voz frente a una fuerza social que ya había dado señales claras de contar con una voz y lenguaje propio.

Ahora bien, lo que comprendieron bien los agentes reformistas fue, por un lado, que a partir de la movilización de una retórica de los afectos podría operarse una imbricación general entre cuerpos, espacios e instituciones, una densa red que pretendía activarse desde el lenguaje poniendo en funcionamiento un doble circuito afectivo que tanto erigía a la ciudad antigua como la moderna y permitía aceptar la instalación de las reformas con la menor resistencia posible. Entendieron que lo que ligaba a los habitantes con su entorno urbano eran, por tanto, los afectos. También tenían claro, por otro lado, que todo cuerpo no es solo el lugar donde se producen las afecciones sino que también es producto de ellas (Safatle 20). Lo que no percibieron es que sería necesario más que un simple cambio retórico y una implicación apenas parcial y figurativa de los habitantes, y que la simple modelación afectiva intencionada puede cobrar formas y efectos insospechados. Cada habitante reclamó, en su momento, un "derecho a la ciudad", ya fuera desde las barricadas 
levantadas por la revuelta de la vacuna o en la voz que poco tiempo después alzarían las mujeres reclamando sus derechos políticos.

Se pone de manifiesto cómo a pesar de la manipulación de determinados afectos, la expectativas, aspiraciones y relaciones afectivas del ser humano con sus espacios, especialmente sus espacios urbanos, suele supera el cálculo planificador. En la efectivamente tensionada relación entre cuerpos y ciudad, los corto circuitos afectivos están a la orden del día.

\section{OBRAS CiTADAS}

Ahmed, Sara. 2015. La política cultura de las emociones. México D.F.: Universidad Nacional Autónoma de México.

Arcos Herrera, Carol. 2014. Autorias femeninas fundacionales: escritoras chilenas y brasileñas del siglo XIX. (1840-1890). Tesis de doctorado en Estudios Latinoamericanos, Universidad de Chile.

Benchimol, Jaime Larry. 1992. Pereira Passos: um Haussmann Tropical. A renovação urbana da cidade do Rio de Janeiro no início do século XX. Rio de Janeiro: Prefeitura da Cidade do Rio de Janeiro.

Buitoni Schroeder, Dulcília. 1986. Imprensa feminina. São Paulo: Editora Ática.

Depetris Chauvin, Irene. 2016. Geographies of Love(lesness). Space and Affectivity in Viajo Porque Preciso, Volto Porque Te Amo (Aïnouz and Gomes, 2009) and Turistas (Alicia Scherson, 2009). Journal of Latin American Cultural Studies 25, 2: 1-17. . 2014. Ecos en el desierto. Paisaje, pueblo y afectividad en Sertão de Acrílico Azul Piscina. Taller de Letras 45: 187-200.

Flatley, Jonathan. 2008. Affective mapping: Melancholia and the politics of modernism. Cambridge: Harvard University.

Gregg, Melisa; Seighworth, Gregory, eds.. 2010. The affect theory reader. Durham: Duke University Press.

Lins, Ivan. 1967. História do positivismo no Brasil. São Paulo: Companhia Editora Nacional.

Paim, Antônio. 1981. O apostolado positivista e a república. Brasília: Editora Universidade de Brasília.

Macón, Cecilia, Losiggio, Daniela. 2017. Afectos politicos. Ensayos sobre actualidad. Buenos Aires: Miño y Dávila.

Moraña, Mabel, Sánchez, Ignacio, eds. 2012. El lenguaje de las emociones. Afectos y cultura en América Latina. Madrid: Iberoamericana, Vervuert.

Nussbaum, Martha C. 2014. Emociones politicas. ¿Por qué el amor es importante para la justicia? Barcelona: Paidós.

Paoli, Paula de. 2013. Entre relíquias e casas velhas. A arquitetura das reformas urbanas de Pereira Passos no centro do Rio de Janeiro. Rio de Janeiro: Fundação de Amparo à Pesquisa do Estado do Rio de Janeiro (Faperj)/Rio Books.

Peluffo, Ana. (2016). En clave emocional. Cultura y afecto en América Latina. Buenos Aires: 
Prometeo Libros.

Pile, Steve. 2009. Emotions and Affect in Recent Human Geography. Transactions of the Institute of British Geographers. Web.

Prefeitura do distrito Federal. 1903. Melhoramentos da cidade projectados pelo Prefeito do Districto Federal Dr. Francisco Pereira Passos. Rio de Janeiro: Typografia da Gazeta de Noticias.

Romero, José Luis. 1999. Latinoamérica: las ciudades y las ideas. Medellín: Editorial Universidad de Antioquia.

Safatle, Vladimir. 2016. O circuito dos afetos. Corpos politicos, desamparo e o fim do indivíduo. Belo Horizonte: Autêntica Editora.

Simmel, Georg. 1903. La metrópolis y la vida mental. Web.

Sevcenko, Nicolau. 1984. A revolta da vacina. Mentes insanas em corpos rebeldes. São Paulo: Brasiliense.

Shouse, Eric. 2005. Feeling, Emotion, Affect. M/C Journal, vol. 8, nº6. Disponible en: http://journal.media-culture.org.au/0512/03-shouse.php Consultado el 1 de agosto de 2019.

Telles, Norma. 2006. "Escritoras, escritas, escrituras". História das mulheres no Brasil. Sáo Paulo: Editora Contexto. 401-442.

Ticineto Clough, Patricia; Halley, Jean, eds. 2007. The Affective Turn: Theorizing the Social. Durham: Duke University Press.

Williams, Raymond. 1988. Marxismo y literatura. Barcelona: Ediciones Península.

\section{REVISTAS}

Kosmos $1904-1909$

Renascença $1904-1908$ 